11

\title{
Поверхностный плазмонный резонанс и агрегативная стабильность комплексов наночастиц серебра с химотрипсином
}

\author{
() А.В. Плющенко ${ }^{1,2}$, К.А. Митусова ${ }^{2}$, Л.Н. Боровикова ${ }^{1}$, А.И. Киппер ${ }^{1}$, О.А. Писарев ${ }^{1,2 q}$ \\ ${ }^{1}$ Институт высокомолекулярных соединений РАН, \\ 199004 Санкт-Петербург, Россия \\ ${ }^{2}$ Санкт-Петербургский политехнический университет Петра Великого, \\ 195251 Санкт-Петербург, Россия \\ "e-mail: chrom79@yandex.ru
}

Поступила в редакцию 23.03.2018 г.

\begin{abstract}
Изучены спектры экстинкции, эффективные размеры и агрегативная стабильность наночастиц серебра и нанокомплексов наночастиц серебра с химотрипсином, полученных реакций химического восстановления нитрата серебра с использованием в качестве восстановителя боргидрида натрия. Показано, что наночастицы серебра, полученные в отсутствие химотрипсина, агрегативно стабильны только при значениях $\mathrm{pH}$ непосредственно после синтеза. Помещение синтезированных наночастиц серебра в буферные растворы со значениями $\mathrm{pH}$ от 3.0 до 12.0 приводило к появлению широкой полосы поглощения в видимой области спектра, что связано с агломерацией наночастиц серебра, которая, по всей видимости, является результатом разрушения двойного электрического слоя, образованного ионами, составляющими боргидрид натрия. Присутствие химотрипсина в реакционной среде приводило к существенным спектральным изменениям. В отличие от наночастиц серебра, синтезированных в отсутствие химотрипсина, для нанокомплексов наночастиц серебра с химотрипсином при изменении $\mathrm{pH}$ форма спектров экстинкции и положение полосы поверхностного плазмонного резонанса сохранялись, при этом в диапазоне рН от 3.0 до 12.0 нанокомплексы наночастиц серебра с химотрипсином сохраняли агрегативную стабильность в растворах в течение месяца. Обнаруженный эффект стабилизации наночастиц серебра в широком диапазоне $\mathrm{pH}$, индуцируемый присутствием химотрипсина в реакционной среде, может быть в дальнейшем использован для разработки методов иммобилизации ферментов на наночастицах биогенных элементов, а также для создания полифункциональных лекарственных препаратов, в которых составляющие нанокомплексов обладают различной биологической активностью.
\end{abstract}

DOI: $10.21883 /$ OS.2018.08.46366.86-18

\section{Введение}

Уникальные физико-химические, оптические и биологические свойства наночастиц серебра (НЧ Ag) обусловливают обширные области их применения: в спектроскопии для детектирования различных аналитов [1], в химическом катализе [2], электронике [3]. В связи с антибактериальными и противовирусными свойствами большой интерес $\mathrm{HЧ} \mathrm{Ag}$ представляют и для медицины $[4,5]$. Поскольку размеры и форма HЧ Ag оказывают значительное влияние на проявляемую ими биологическую активность, большое значение имеет выбор метода синтеза НЧ [6]. Наиболее широко используемым методом синтеза НЧ $\mathrm{Ag}$ является метод химического восстановления, преимуществами которого являются получение наночастиц малого размера, высокий выход продукта реакции, а также простота осуществления и экономичность синтеза $[7,8]$. Способ восстановления солей $\mathrm{Ag}$ боргидридом натрия $\left(\mathrm{NaBH}_{4}\right)$ является наиболее распространенным в процессах синтеза $\mathrm{HЧ} \mathrm{Ag}$ как в гомогенных, так и в гетерогенных системах. Его использование за счет большой разности редокс-потенциалов $\mathrm{NaBH}_{4}(-1.24 \mathrm{~V}$, в щелочной среде) и $\mathrm{Ag}(0.8 \mathrm{~V})$ должно приводить при значительном избытке $\mathrm{NaBH} 4$ к получению гомогенных по составу и небольших частиц $(30-70 \mathrm{~nm})[9]$.

Высокая поверхностная энергия НЧ способствует их агрегативной нестабильности. Нестабилизированные HЧ Ag подвергаются быстрому окислению и агрегируют в растворах, что затрудняет их практическое использование. Для получения агрегативно устойчивых в течение длительного времени $\mathrm{HЧ} \mathrm{Ag}$ с заданными свойствами необходимо использовать соответствующие стабилизаторы.

Основными факторами, способствующими стабилизации $\mathrm{HЧ} \mathrm{Ag}$, являются электростатический и стерический факторы [10]. Было показано, что стерическая стабилизация $\mathrm{HЧ} \mathrm{Ag}$ полимерами и электростерическая стабилизация полиэлектролитами более эффективны по сравнению с только электростатической стабилизацией (цитрат ионами или $\mathrm{NaBH}_{4}$ ) [11]. Для электростерической стабилизации НЧ также могут быть использованы биомакромолекулы, взаимодействие с которыми расширяет спектр биологической активности НЧ и позволяет создавать гибридные органо-неорганические нанокомплексы, обладающие полифункциональной биологической активностью $[10,12,13]$.

Проявление поверхностного плазмонного резонанca (ППР) НЧ Ag в спектрах экстинкции приводит к воз- 
можности систематически исследовать свойства НЧ $\mathrm{Ag}$ методами УФ и видимой спектроскопии. Показано, что форма, положение и интенсивность полосы ППР значительно зависят от размеров и формы НЧ Ag, а также от их диэлектрического окружения и взаимодействия со стабилизатором [14]. Соответственно исследование спектров экстинкции НЧ $\mathrm{Ag}$ и нанокомплексов на их основе предоставляет возможность изучать образование их комплексов с выбранным стабилизатором, а также изменение размеров и агрегацию НЧ $\mathrm{Ag}$ при варьировании физико-химических условий среды.

В настоящей работе в качестве стабилизатора $\mathrm{HЧ} \mathrm{Ag}$ был выбран протеолитический фермент химотрипсин (XT), широко применяемый в медицине. Нанокомплексы на основе ХТ и НЧ Ag, обладающие одновременно протеолитическими и бактерицидными свойствами, способны стать основой полифункциональных лекарственных препаратов для лечения ран, ожогов и других воспалительных процессов [12].

Цель настоящей работы - изучение ППР и агрегативной стабильности НЧ $\mathrm{Ag}$ и нанокомплексов НЧ $\mathrm{Ag}-\mathrm{XT}$, полученных реакцией химического восстановления нитрата серебра $\left(\mathrm{AgNO}_{3}\right)$ с использованием в качестве восстановителя боргидрида натрия $\left(\mathrm{NaBH}_{4}\right)$.

\section{Методика эксперимента}

В работе использовали $\alpha$-химотрипсин (КФ 3.4.21.1, „AppliChem“, Германия), а также $\mathrm{AgNO}_{3}, \mathrm{NaBH}_{4}$, натрия гидроксид $(\mathrm{NaOH})$, уксусную кислоту $\left(\mathrm{CH}_{3} \mathrm{COOH}\right)$, ортофосфорную кислоту $\left(\mathrm{H}_{3} \mathrm{PO}_{4}\right)$ и борную кислоту $\left(\mathrm{H}_{3} \mathrm{BO}_{3}\right)$ - все перечисленные реактивы производства „Вектон“ (Россия).

Регистрацию спектров оптического поглощения проводили на спектрофотометре Specord M-40 („Carl Zeiss“, Германия) в кварцевых кюветах $1 \times 1 \mathrm{~cm}$. Для измерения $\mathrm{pH}$ растворов использовался $\mathrm{pH}$-метр-милливольтметр лабораторный типа рН-673 M („Измерительная техника", Россия).

Средние гидродинамические радиусы $\left(R_{h}\right)$ наноструктур определяли методом динамического рассеяния света (ДРС) [15]. Корреляционную функцию интенсивности рассеянного света получали с помощью коррелятора Photocor-FC с числом каналов 288 (ООО „Фотокор“, Россия). Анализ корреляционной функции осуществляли с помощью программы обработки данных ДРС Dynals („Гелиос“, Россия). Из полученных коэффициентов диффузии $D$ находили гидродинамический радиус эквивалентной сферы $R_{h}$ по уравнению Эйнштейна-Стокса

$$
R_{h}=k T / 6 \pi D \eta_{S}
$$

где $k$ - константа Больцмана, $\eta_{S}-$ вязкость растворителя, $T$ - температура.

Исследования методом просвечивающей электронной микроскопии (ПЭМ) проводили на электронном микроскопе BS-500 („Tesla“, Чехия).
Синтез НЧ Ag осуществлялся в ходе реакции восстановления $\mathrm{AgNO}_{3} \mathrm{NaBH}_{4}$ в водной среде при атмосферном давлении и температуре $4^{\circ} \mathrm{C}$ при 24-кратном избытке количества $\mathrm{NaBH}_{4}$. Для этого в реакционную колбу помещалось $0.5 \mathrm{ml} 0.1575$ масс.\% $\mathrm{AgNO}_{3}, 0.2 \mathrm{ml}$ 2.1 масс.\% $\mathrm{NaBH}_{4}$ и $9.3 \mathrm{ml}$ дистиллированной воды. Значение $\mathrm{pH}$ растворов после синтеза составляло 9.2-9.4. При этих значениях $\mathrm{pH}$ растворы НЧ $\mathrm{Ag}$ сохраняли агрегативную стабильность достаточно длительное время в отсутствие дополнительного стабилизатора.

Для синтеза нанокомплексов $\mathrm{HЧ} \mathrm{Ag}-\mathrm{XT}$ в реакционную колбу помещалось $0.5 \mathrm{ml} 0.1575$ масс.\% $\mathrm{AgNO}_{3}$, $0.2 \mathrm{ml} 2.1$ масс.\% $\mathrm{NaBH}_{4}, 5 \mathrm{ml} \quad 0.2$ масс.\% ХТ и $4.3 \mathrm{ml}$ дистиллированной воды. В этом случае значение $\mathrm{pH}$ растворов составляло 8.2-8.3.

Для приготовления универсального буферного раствора готовили $0.1 \mathrm{H}$. растворы $\mathrm{CH}_{3} \mathrm{COOH}, \mathrm{H}_{3} \mathrm{PO}_{4}$ и $\mathrm{H}_{3} \mathrm{BO}_{3}$ и смешивали их в равных объемных соотношениях. Полученный раствор разбавляли дистиллированной водой в 10 раз. Изменение значения $\mathrm{pH}$ в универсальном буфере достигалось добавлением различных объемов 1 н. $\mathrm{NaOH}$.

\section{Результаты и их обсуждение}

На рис. 1 представлена кинетика изменения спектров экстинкции НЧ $\mathrm{Ag}$, когда их агрегативная устойчивость обеспечивалась ионами $\mathrm{NaBH}_{4}$. Можно полагать, что в этом случае осуществлялась электростатическая стабилизация. Из анализа спектров экстинкции следует, что со временем понижалось абсолютное значение оптической плотности, при этом на вторые сутки после синтеза происходил сдвиг полосы ППР НЧ Ag с 390 до $400 \mathrm{~nm}$ (рис. 1). Уширение пика и его сдвиг в длинноволновую область на спектрах экстинкции наблюдаются с увеличением размера частиц [14]. Изучение кинетики изменения гидродинамического радиуса НЧ $\mathrm{Ag}$ (рис. 1, вставка) показало постепенное укрупнение образовавшихся частиц, абсолютное значение исходного $R_{h}$ ко-

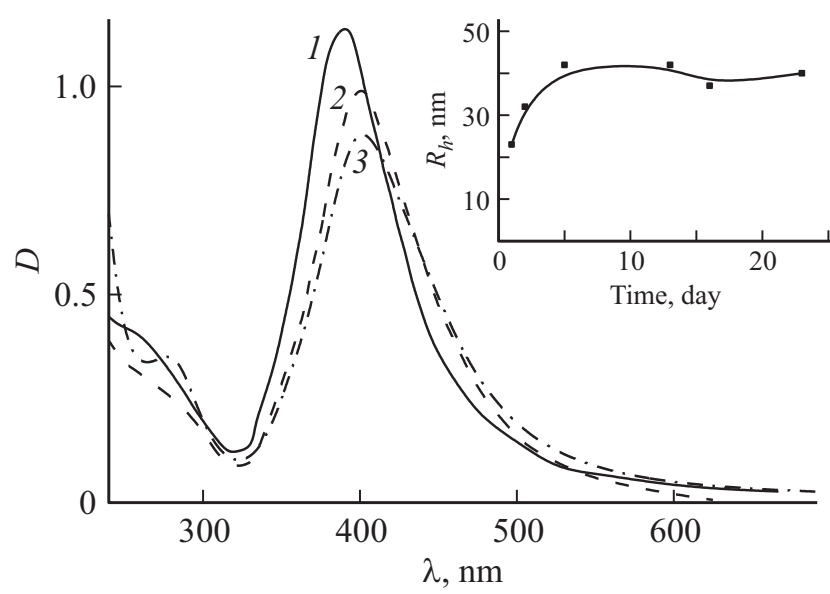

Рис. 1. Спектры экстинкции наночастиц $\mathrm{Ag}$ на 1 (1), 2 (2) и 23 (3) сутки после синтеза. Вставка: кинетика изменения гидродинамического радиуса $\mathrm{HЧ} \mathrm{Ag.}$ 

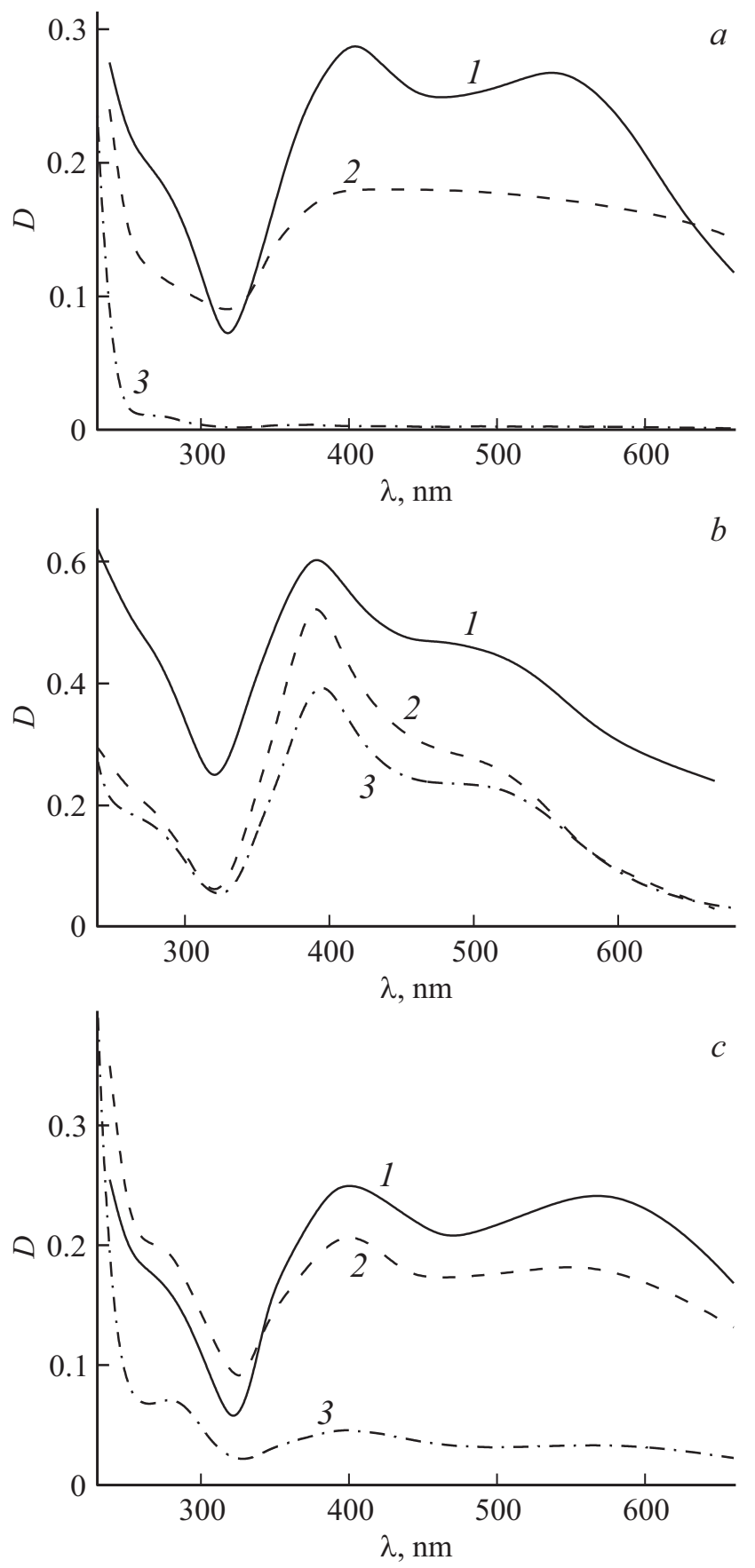

Рис. 2. Спектры экстинкции наночастиц $\mathrm{Ag}$ в буферном растворе при $\mathrm{pH} 5.0(a), \mathrm{pH} 7.0(b)$ и $\mathrm{pH} 11.0(c)$ на 1 (1), 4 (2), 12 (3) сутки.

торых составляло $\sim 23 \mathrm{~nm}$. В течение двух недель $R_{h}$ достигал постоянного значения $(\sim 40 \mathrm{~nm})$. Очевидно, что увеличение $R_{h}$ НЧ с $\sim 23$ до $\sim 40 \mathrm{~nm}$ приводило к сдвигу полосы ППР с 390 до $400 \mathrm{~nm}$.

Отметим, что синтезированные НЧ Ag были агрегативно устойчивы при значениях $\mathrm{pH}$ после синтеза (pH 9.2-9.4) в течение месяца, несмотря на то, что с течением времени их эффективные размеры увеличивались.
Растворы НЧ Ag с различными значениями $\mathrm{pH}$ были получены следующим образом: $1 \mathrm{ml}$ раствора НЧ после синтеза смешивался с $5 \mathrm{ml}$ универсального буфера при различных значениях $\mathrm{pH}$ (от 3.0 до 12.0). При таком соотношении объемов изменения $\mathrm{pH}$ универсального буфера не наблюдалось.

В полученных системах была изучена кинетика изменения спектральных и размерных характеристик. Следует отметить, что агрегативная стабильность НЧ $\mathrm{Ag}$ сохранялась только первые 4 дня, в дальнейшем наблюдалось осаждение НЧ Ag и соответственно обесцвечивание растворов.

На рис. 2 представлены спектры экстинкции полученных систем при рН 5.0, 7.0 и 11.0. В сравнении со спектрами НЧ Ag сразу после синтеза спектры экстинкции НЧ Ag претерпевали значительную трансформацию: наряду с полосой ППР в области $390 \mathrm{~nm}$ в видимой области спектров появлялась широкая полоса поглощения, максимум которой зависел от $\mathrm{pH}$ среды и приходился на $\sim 540$ (при рН 5.0), 500 (при рН 7.0) и $\sim 570 \mathrm{~nm}$ (при рН 11.0). Появление вторых пиков на спектрах экстинкции может быть связано с геометри-

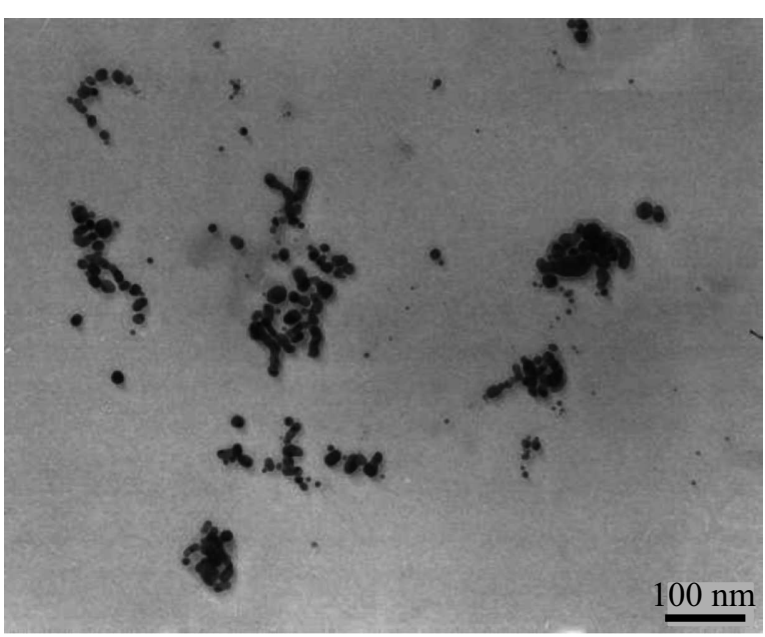

$a$

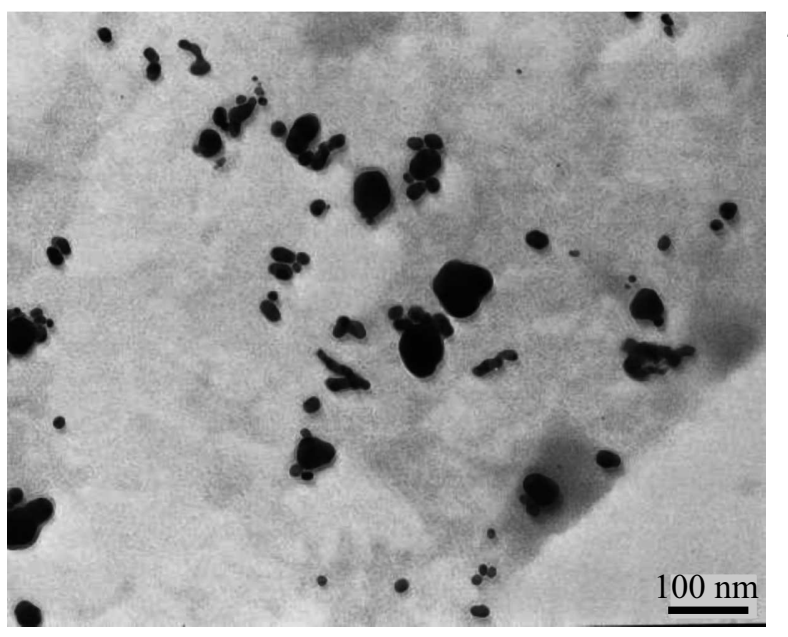

Рис. 3. ПЭМ-изображение наночастиц $\mathrm{Ag}$ в исходном раствоpe $(a)$ и наночастиц $\mathrm{Ag}$, помещенных в буферный раствор с pH $11.0(b)$. 


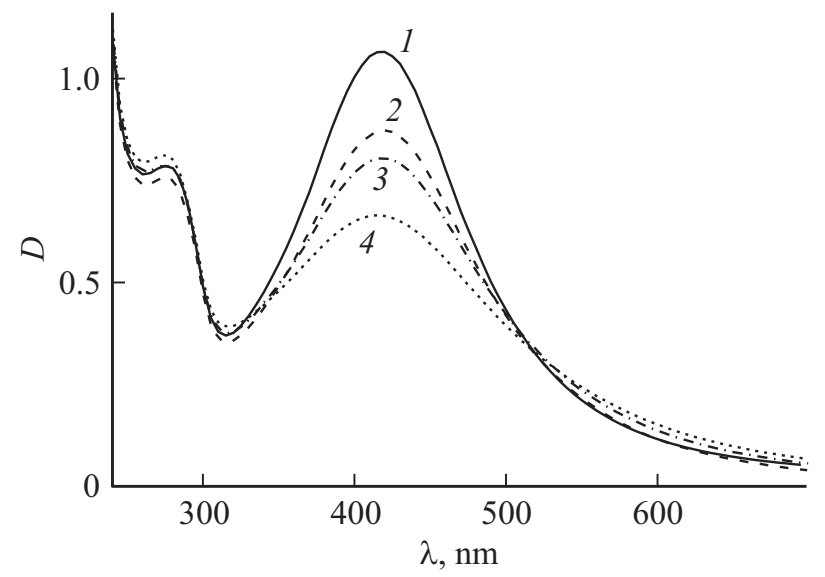

Рис. 4. Спектры экстинкции нанокомплексов $\mathrm{HЧ} \mathrm{Ag}-\mathrm{XT}$ на $2(1), 4(2), 7$ (3) и 27 (4) сутки после синтеза.

ческой анизотропией $\mathrm{HЧ} \mathrm{Ag}$, а также с образованием агломератов [16].

На рис. 3, $a$ приведено ПЭМ-изображение исходных HЧ $\mathrm{Ag}(\mathrm{pH} 9.2-9.4)$, на котором видны квазисферические частицы с диаметром $20 \pm 5 \mathrm{~nm}$. После помещения НЧ $\mathrm{Ag}$ в буферный раствор с $\mathrm{pH} 11.0$ наряду с НЧ исходного размера наблюдались частицы с диаметром от 40 до $70 \mathrm{~nm}$ (рис. $3, b$ ). Таким образом, появление дополнительного пика на спектрах экстинкции $\mathrm{HЧ} \mathrm{Ag}$ в буферных растворах, вероятно, обусловлено ППР агломератов НЧ Ag. Можно полагать, что под влиянием $\mathrm{pH}$ среды стабилизирующий двойной электрический слой, образованный ионами, составляющими $\mathrm{NaBH}_{4}$, и окружающий наночастицу, разрушался, что приводило к агрегации и осаждению частиц.

Далее были исследованы НЧ Ag, стабилизированные молекулами ХТ. Для получения нанокомплекса НЧ $\mathrm{Ag}-\mathrm{XT}$ реакцию синтеза НЧ $\mathrm{Ag}$ проводили в присутствии XТ. С одной стороны, в ходе реакции восстановления ХТ являлся стабилизатором $\mathrm{HЧ} \mathrm{Ag}$ в растворе, с другой стороны, осуществлялась иммобилизация фермента на НЧ $\mathrm{Ag}$.

Спектры экстинкции нанокомплексов $\mathrm{HЧ} \mathrm{Ag}-\mathrm{XT}$ характеризовались двумя пиками поглощения: первый (при $275 \mathrm{~nm}$ ) соответствовал максимуму поглощения XT, а второй (при $415-420 \mathrm{~nm}$ ) соответствовал ППР НЧ $\mathrm{Ag}$ (рис. 4). Максимум поглощения нестабилизированных НЧ Ag находился в области $400 \mathrm{~nm}$. Таким образом, наблюдался гипсохромный сдвиг пика поглощения ХT на $\sim 5 \mathrm{~nm}$ (максимум поглощения нативного ХT соответствует $280 \mathrm{~nm}$ ) и батохромный сдвиг полосы ППР HЧ Ag на 15-20 nm. Это свидетельствовало об образовании нанокомплексов НЧ Ag-XТ. С течением времени абсолютное значение оптической плотности растворов понижалось, что может быть связано с окислением поверхностного слоя $\mathrm{Ag}[17,18]$.

Кинетика изменения спектральных и размерных характеристик, а также агрегативная стабильность нанокомплексов НЧ $\mathrm{Ag}-\mathrm{XT}$ были изучены в диапазоне
pH от 3.0 до 12.0. На рис. 5 представлены спектры экстинкции нанокомплексов $\mathrm{HЧ} \mathrm{Ag}-\mathrm{XT}$, помещенных в буферные растворы со значениями $\mathrm{pH}$ 5.0, 7.0 и 11.0. В отличие от НЧ $\mathrm{Ag}$, синтезированных в отсутствие XT, для нанокомплексов $\mathrm{HЧ} \mathrm{Ag-XT} \mathrm{форма} \mathrm{спектров} \mathrm{экстинк-}$ ции и положение ППР сохранялись. Можно полагать, что ХТ, образуя комплексы с $\mathrm{HЧ} \mathrm{Ag}$, препятствовал их агрегации. Этот факт также подтверждается данными ПЭМ, согласно которым основная часть $\mathrm{HЧ} \mathrm{Ag}$, стаби-
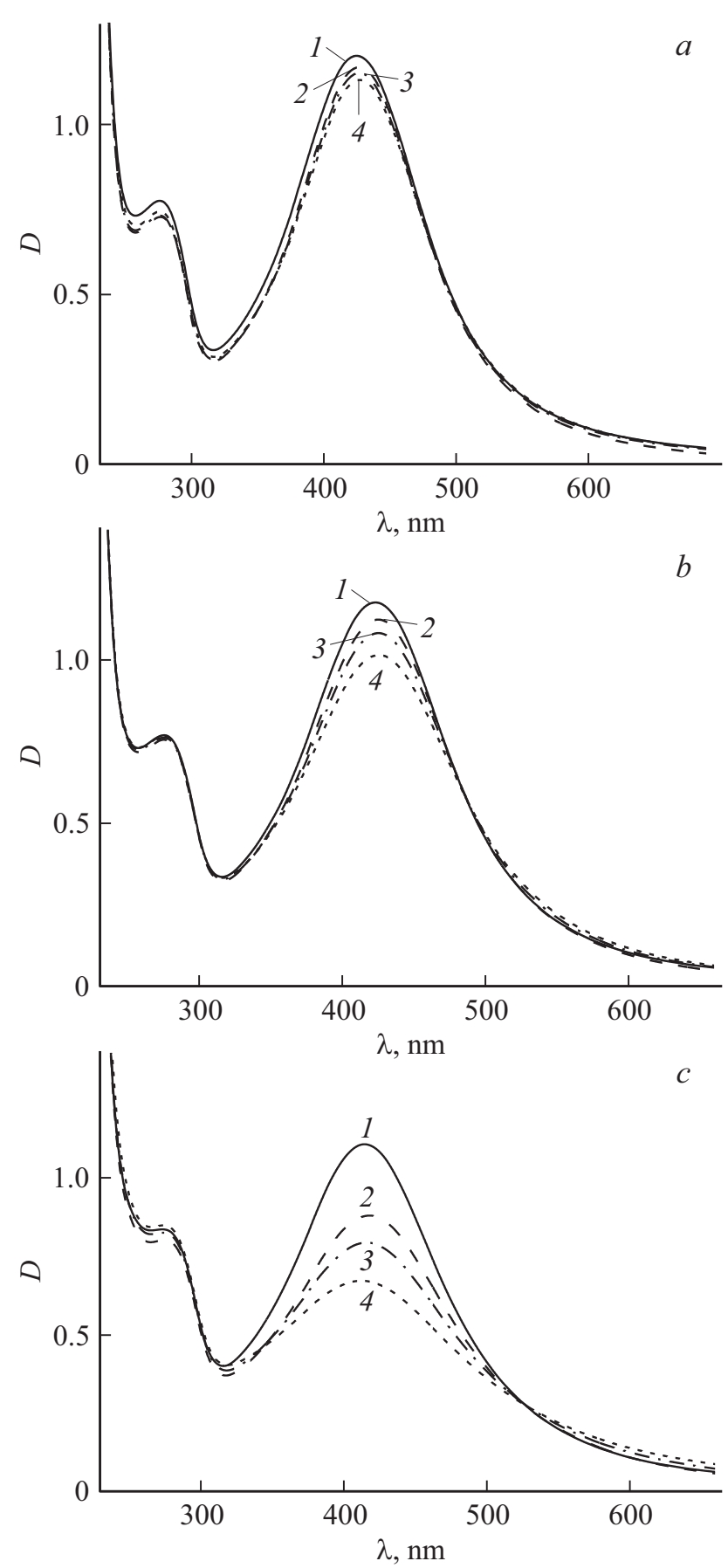

Pис. 5. Спектры экстинкции нанокомплексов $\mathrm{HЧ} \mathrm{Ag}-\mathrm{XT}$ в буферном растворе при рН $5.0(a), \mathrm{pH} 7.0(b)$ и рН $11.0(c)$ на $1(1), 3(2), 6(3)$ и $26(4)$ сутки. 

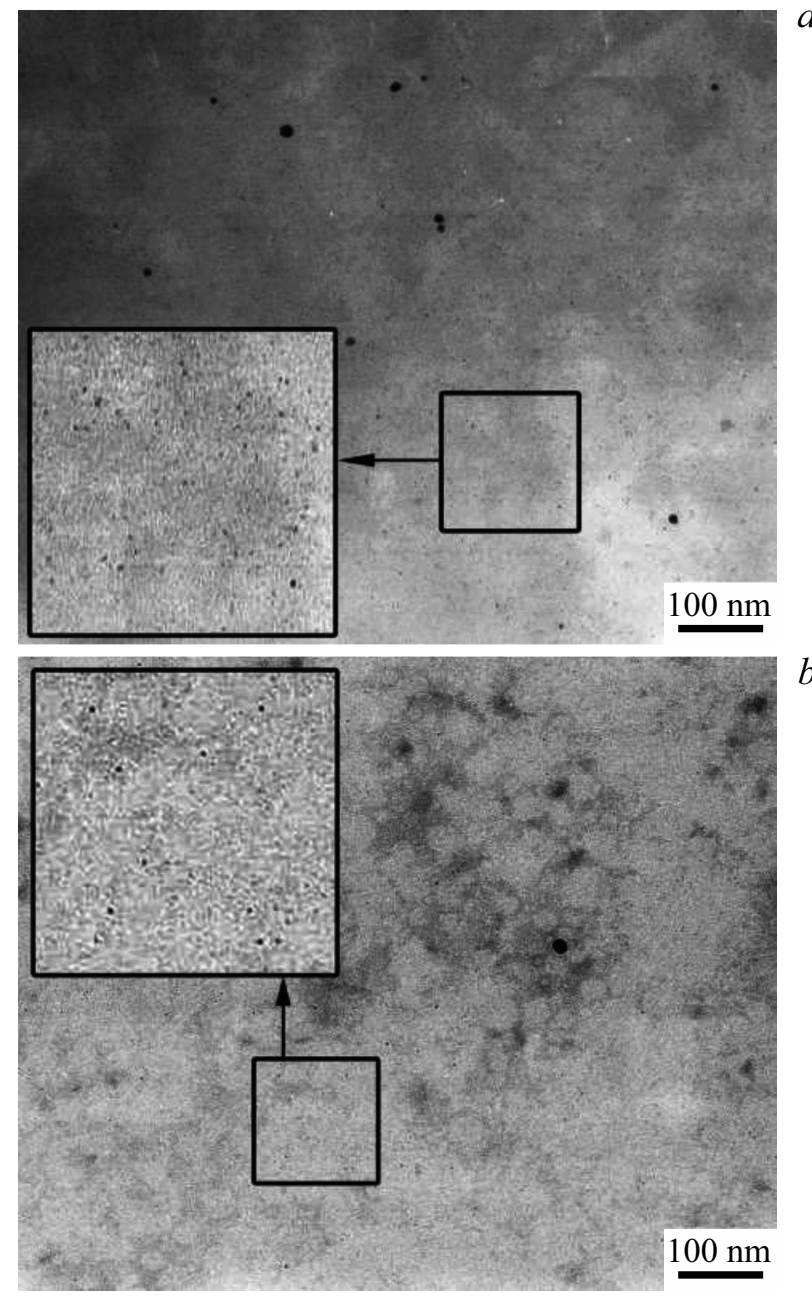

Рис. 6. ПЭМ-изображение нанокомплексов НЧ $\mathrm{Ag}-\mathrm{XT}$ в исходном растворе $(a)$ и нанокомплексов НЧ $\mathrm{Ag}-\mathrm{XT}$, помещенных в буферный раствор с $\mathrm{pH} 8.0(b)$.

лизированных ХТ, представляла собой квазисферические частицы с диаметром до $5 \mathrm{~nm}$ (рис. 6, $a$ ). После помещения нанокомплексов НЧ $\mathrm{Ag}-\mathrm{XT}$ в буферный раствор с pH 8.0 размеры НЧ Ag сохранялись (рис. 6, $b$ ), при этом в диапазоне $\mathrm{pH}$ от 3.0 до 12.0 нанокомплексы НЧ AgХТ сохраняли агрегативную стабильность в растворах в течение месяца.

\section{Заключение}

В работе исследовано влияние протеолитического фермента ХТ на положение ППР и агрегативную стабильность НЧ Ag. В отсутствие ХТ при проведении реакции восстановления $\mathrm{AgNO}_{3} \mathrm{NaBH}_{4}$ показана агрегация НЧ $\mathrm{Ag}$ при изменении рН среды, что проявлялось в появлении широкой полосы поглощения в видимой области спектров экстинкции. Обнаружена способность ХT образовывать комплексы с НЧ Ag и предотвращать их агрегацию, что соответственно позволяет стабилизировать НЧ $\mathrm{Ag}$ в широком диапазоне $\mathrm{pH}$.

В связи с полученными результатами становится достаточно перспективной систематическая разработка методов модификации ферментов НЧ биогенных элементов, поскольку значительное увеличение удельной поверхности НЧ (в сравнении с известными носителями) должно приводить к реализации многоточечного взаимодействия фермента с НЧ и облегчению диффузионного транспорта субстрата к активному центру фермента. Кроме того, в медицине и в различных биотехнологических процессах часто необходимо использовать ферменты при неоптимальных значениях $\mathrm{pH}$ среды. Поэтому разработка новых методов их иммобилизации, позволяющих сохранить активность фермента при неоптимальных условиях среды, относится к одной из важнейших задач современной биотехнологии.

\section{Список литературы}

[1] Терентьева Е.А., Апяри В.В., Кочук Е.В., Дмитриенко С.Г., Золотов Ю.А. // Журн. аналит. химии. 2017. Т. 72. № 11. C. 978; Terenteva E.A., Apyari V.V., Kochuk E.V., Dmitrienko S.G., Zolotov Yu.A. // J. Analyt. Chem. 2017. V. 72. N 11. P. 1138. doi 10.1134/S1061934817120097

[2] Bhosale M.A., Bhanage B.M. // Current Organic Chemistry. 2015. V. 19. N 8. C. 708.

[3] Alshehri A.H., Jakubowska M., Mlozniak A., Horaczek M., Rudka D., Free C., Carey J.D. // ACS Appl. Mater. Interfaces. 2012. V. 4. N 12. P. 7007. doi 10.1021/am3022569

[4] Tran Q.H., Nguyen V.Q., Le A.T. // Adv. Nat. Sci.: Nanosci. Nanotechnol. 2013. V. 4. N 3. P. 033001. doi 10.1088/20436262/4/3/033001

[5] Wei L., Lu J., Xu H., Patel A., Chen Z.S., Chen G. // Drug Discov. Today. 2015. V. 20. N 5. P. 595. doi 10.1016/j.drudis.2014.11.014

[6] Morones J.R., Elechiguerra J.L., Camacho A., Holt K., Kouri J.B., Ramirez J.T., Yacaman M.J. // Nanotechnology. 2005. V. 16. N 10. P. 2346. doi 10.1088/0957-4484/16/10/059

[7] Song K.C., Lee S.M., Park T.S., Lee B.S. // Korean J. Chem. Eng. 2009. V. 26. N 1. P. 153. doi 10.1007/s11814-009-0024-y

[8] Оленин А.Ю., Лисичкин Г.В. // Усп. хим. 2011. Т. 80. № 7. C. 635; Olenin A.Y., Lisichkin G.V. // Russ. Chem. Rev. 2011. V. 80. N 7. P. 605. doi 10.1070/RC2011v080n07ABEH004201

[9] Помогайло А.Д., Розенберг А.С., Джсардималиева Г.И. // Усп. хим. 2011. Т. 80. С. 272; Pomogailo A.D., Rosenberg A.S., Dgardimalieva G.I. // Russ. Chem. Rev. 2011. V. 80. N 3. P. 257.

[10] Zewde B., Ambaye A., Stubbs J.III, Dharmara R. // JSM Nanotechnol. Nanomed. 2016. V. 4. N 2. P. 1043.

[11] El Badawy A.M., Luxton T.P., Silva R.G., Scheckel K.G., Suidan M.T., Tolaymat T.M. // Environ. Sci. Technol. 2010. V. 44. N 4. P. 1260 . doi $10.1021 / \mathrm{es} 902240 \mathrm{k}$

[12] Писарев О.А., Титова А.В., Боровикова Л.Н., Киппер А.И., Ворошилова Т.М., Панарин Е.Ф. // Известия АН. Сер. хим. 2016. № 3. С. 790; Pisarev O.A., Titova A.V., Borovikova L.N., Kipper A.I., Panarin E.F., Voroshilova T.M. // Russian Chemical Bulletin. 2015. V. 65. N 3. P. 790. doi 10.1007/s11172-016-1375-2 
[13] Titova A., Borovikova L., Kipper A., Pisarev O. // Chemistry Research J. 2017. V. 2. N 5. P. 204.

[14] Moores A., Goettmann F. // New J. Chem. 2006. V. 30. N 8. P. 1121. doi 10.1039/B604038C

[15] Brown $W$. Dynamic Light Scattering: the Method and Some Application. Oxford: Clarondon Press, 1993. 617 p.

[16] Novotny L., Hech B. Principles of Nano-Optics. 2nd Edition. Cambridge: Cambridge University Press, 2012. 578 p.

[17] Yin Y., Li Z.Y., Zhong Z., Gates B., Xia Y., Venkateswaran S. // J. Mater. Chem. 2002. V. 12. N 3. P. 522-527. doi 10.1039/B107469E

[18] Chen M., Wang L.Y., Han J.T. // J. Phys. Chem. B. 2006. V. 110. N 23. P. 11224. doi 10.1021/jp061134n 